\title{
Evaluation of HTGR Cogeneration Plant Load-Follow Operations Capability
}

\author{
Xing L. Yan \\ Tel: +81-29-266-7719 \\ yan.xing@jaea.go.jp
}

\author{
Hiroyuki Sato \\ Tel: +81-29-266-7718 \\ sato.hiroyuki@jaea.go.jp \\ Japan Atomic Energy Agency \\ Oarai-machi, Higashi-ibaraki-gun \\ Ibaraki-ken 311-1394, Japan
}

\author{
Yukio Tachibana \\ Tel: +81-29-266-7605 \\ tachibana.yukio@jaea.go.jp
}

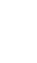

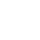


on newly-proposed control methods. Section 4 discusses simulation results of the whole plant performance against a bounding load following event. The conclusions of the study are given in Section 5 .

\section{LOAD-FOLLOW REQUIREMENT}

Industries like steel and oil producers consume intensive heat and power and are looking for more efficient and cleaner energy sources to cut costs and CO2 emissions. A 4,000 ton/day direct reduction steelmaking plant, currently the world's largest scale, is estimated to consume about 800 MWt of heat and 200 MWe of electricity in the furnaces and operation utilities. Two HTGRs suffice to supply all energy and hydrogen needs of the process while making it free of $\mathrm{CO} 2$ emission.

In both developed and developing economies, small-sized nuclear reactors are increasingly considered to help meet industrial and remote energy needs that can involve significant load following. In 2009, electric demand in Japan peaks in summer by $50 \%$ over winter while daily peak is even more pronounced. The load can climb by about $1 \%$ of base load per minute during early hours of a business day. On the other hand, the winter electricity demand in Kazakhstan is $50 \%$ more than in it consumes summer. In arid regions, electricity demand is both seasonal and diurnal.

Nuclear reactor plants are capital intensive such that construction expense makes up one third or more of cost of energy production. Economics would thus prescribe a combined base load even in frequent load following. Assuming that historical or anticipated load curves for industrial or remote user are known, it is possible to size a cogeneration plant to generate maximum electricity, since it must be supplied in real time, and use the balance of plant thermal capacity to generate heat. Any shortfall and surplus of thermal energy in real time should be managed by stand-by heater or storage of heat-processed product to ensure supply. Note that this strategy certainly has ramification on the economics of a specific cogeneration site beyond the scope of this general study. Moreover, it is necessary for the cogeneration plant to follow the rate of electricity peaking in the load curves. The rates typically include $\pm 5 \%$ per minute and $\pm 10 \%$ step of the base electric load.

\section{HTGR PLANT DESIGN}

JAEA developed and has, since 1998, been operating the $30 \mathrm{MWt}$ and $950 \mathrm{oC}$ high temperature engineering test reactor $[14,15]$. It is based on the know-how gained in the HTTR and additional development of nuclear plant technologies including power conversion and heat process equipment that JAEA has developed the basic design for the commercial GTHTR300C, a Generation-IV HTGR system to cogenerate electricity and heat or hydrogen at high thermal efficiency [16-17]. As schematically shown in Figure 1, the GTHTR300C consists of a 600MWt HTGR, an intermediate heat exchanger (IHX) for $900 \mathrm{oC}$ process heat supply to a high-temperature hydrogen production plant, a direct-cycle recuperated gas turbine for reactor coolant circulation and power conversion, and a precooler to discharge the waste heat of the power conversion cycle. Although not shown, the waste heat of $160 \mathrm{oC}$ removed in the precooler can supply desalination and district heating without penalty to power generation. The closed intermediate helium loop circulates hot helium from IHX to the distant hydrogen plant and completes necessary environmental and material separation between the nuclear and chemical plants.

The helium gas turbine is a single-shaft, axial-flow design having six turbine stages and twenty compressor stages. The gas turbine is rated at 280 MWe and 3,600 rpm and drives a synchronous generator from shaft cold end. The machine design mostly complies with established industrial practice in heavy-duty combustion gas turbine. The hydrogen production plant is ideally based on a thermochemical iodine sulfur (IS) process or a steam electrolysis process. The IS process involves three inter-cyclic thermochemical reactions for the decomposition of water molecules into hydrogen and oxygen gas products. The process consumes water as the only material feedstock and all other process materials used are chemical reagents. The heat and electricity consumed by the process are drawn in-house as shown in Figure 1. The heat supports the endothermic decomposition reactions and the electricity drives the electrolyzers, gas circulators, pumps and other utilities.

The GTHTR300C design includes a new proposal of control strategy to accomplish cogeneration load following. Two prerequisites of the proposal are 1) that the reactor temperature and thermal power remain unchanged in order to permit rapid and frequent control including daily peak electricity generation and 2) that the efficiency of the power generation remains constant. The cogeneration ratio is adjusted by varying the heat rate through the variable speed circulator in the IHX secondary loop and by simultaneously regulating turbine power output to follow electric load but without changing vital gas turbine aerodynamic performance parameters such as gas velocity, temperature, and pressure ratio. This is found to be achievable by regulating turbine mass flow rate indirectly by monitoring and controlling turbine inlet temperature, $\mathrm{Tt}$, constant through flow valve CV4 and by regulating turbine inlet pressure, $\mathrm{Pr}$, to follow electric load through primary coolant inventory control by flow valves IV1 and IV2, which connects to helium storage and supply tanks.

In terms of equipment sizing, the greater the controllable range of cogeneration load following is required, the larger the size of flow valve CV4 will be. On the other hand, the faster the load following is desired, the larger the inventory control valves IV1 and IV2 would be. While the inventory valves are found to be of small in all practical control needs, the flow valve CV4 can be large in a large plant with extensive range of load following because of the low pressure head or large flow coefficient associated with the specific installation arrangement. In this case, multiple units of smaller size operating in parallel have installation and operation advantages over a large-size single valve unit, including control sequencing and redundancy as well as that the number of valves in the multi-valve unit can be added or subtracted according to the extent of load following as required by the plant user.

HTGR core thermal power will in general respond to change in coolant flow due to resulting temperature change from affected coolant cooling and further negative reactivity 


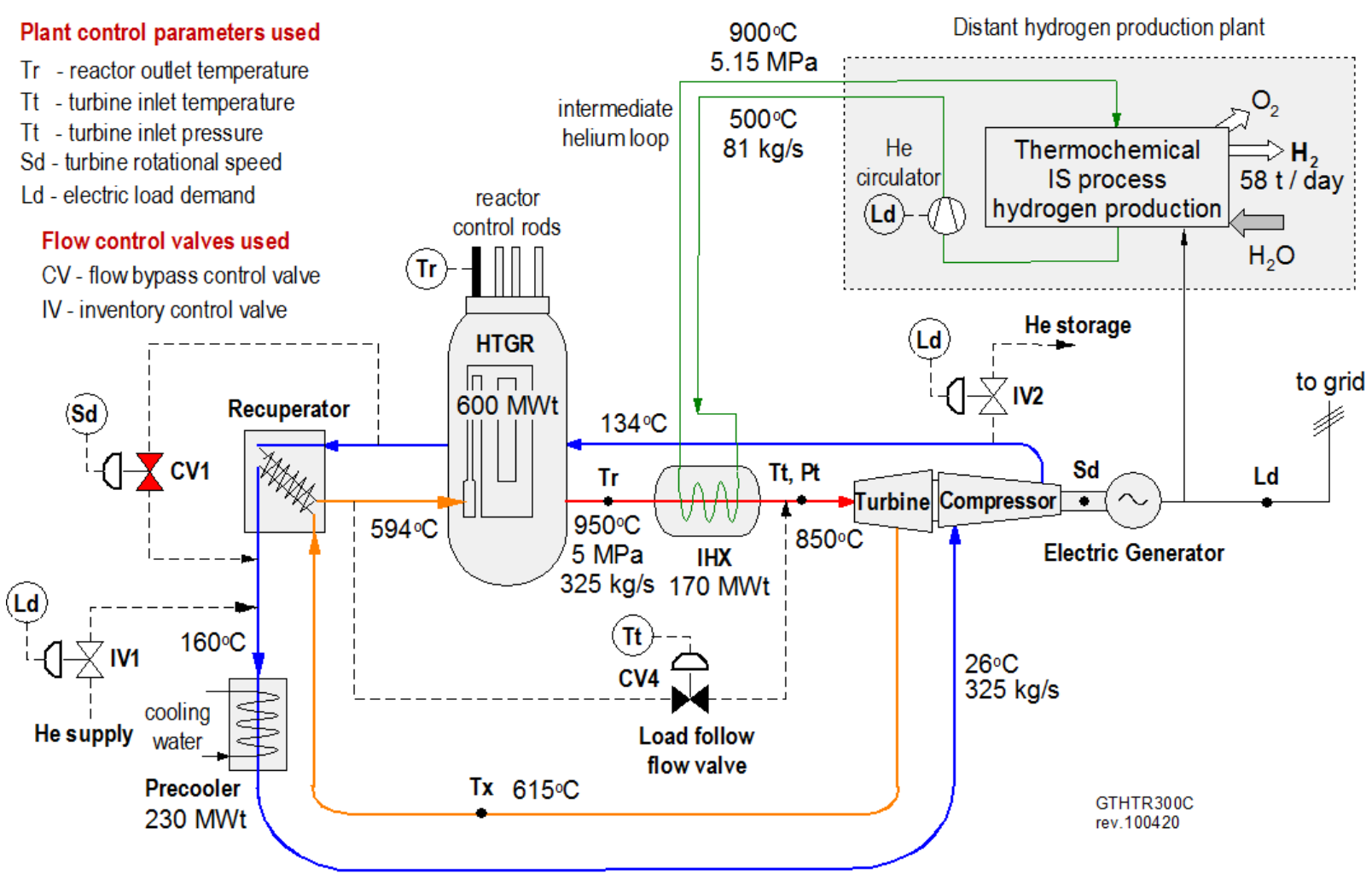

Figure 1: Cycle process and control of the GTHTR300C, an HTGR plant designed for cogeneration for electricity and high-temperature heat or further hydrogen.

feedback of temperature. The good performance of this design feature has been obtained in the tests of the HTTR. As

a result, GTHTR300C takes the same approach to controlling the core power during load following, that is, through coolant control and reactivity feedback. Use of control rods is only necessary in startup and shutdown, in long-term operation at reduced core temperature, and to compensate fuel burnup.

\section{SIMULATION RESULTS}

A plant system simulation model is constructed by building the component models and material database specific to the GTHTR300C and then merging them with the standard models and solver of the RELAP5 MOD3. Description on the development of the simulation model can be found elsewhere $[19,20]$ and is not repeated here. The reactor is represented by nuclear fission of point neutron kinetics with various sources of reactivity feedback, fuel blocks with power generation and heat transfer in hot and average coolant channels, the reflector blocks with coolant channels, reactor upper and lower gas plena, control rod flow channels, core support cooling flow path, and RPV and vessel cooling flow path. The recuperator model includes the high pressure fluid, low pressure fluid, and metal plate surface. The precooler model includes the helium side, cooling water side, and helical-coil metal tube surface. The IHX model contains the primary coolant side, the intermediate loop helium side, and metal tubular surface. The flow of the intermediate helium loop can be controlled by varying the helium circulator speed with variable speed motor to regulate the process heat rate of the IHX. Heat transfer correlations are incorporated corresponding to the types of heat exchangers used in the plant. The major component physical models and material properties for the reactor, the heat exchangers, and the helium gas turbine have been validated by the HTTR operations and additional mock-up tests [11, 13].

Table 1. Base heat and power cogeneration parameters

\begin{tabular}{|l|c|c|c|}
\hline & Reactor & IHX heat rate & Gas turbine \\
\hline Power & $600 \mathrm{MWt}$ & $170 \mathrm{MWt}$ & $203 \mathrm{MWe}$ \\
\hline Temperature & $950^{\circ} \mathrm{C}$ outlet & $\begin{array}{c}900^{\circ} \mathrm{C} \\
\text { heat sent out }\end{array}$ & $\begin{array}{c}850^{\circ} \mathrm{C} \\
\text { turbine inlet }\end{array}$ \\
\hline Pressure & $5 \mathrm{MPa}$ & $5 \mathrm{MPa}$ & $5 \mathrm{MPa}$ \\
\hline Gas flow & $325 \mathrm{~kg} / \mathrm{sec}$ & $81 \mathrm{~kg} / \mathrm{sec}$ & $325 \mathrm{~kg} / \mathrm{sec}$ \\
\hline
\end{tabular}

The base heat and power ratio, which is application specific, sets maximum heat rate of the plant. The base cogeneration parameters are summarized in Table 1. In this cogeneration mode, the reactor outlet coolant of $950 \mathrm{oC}$ enters the primary side of the IHX and heats the secondary helium to $900 \mathrm{oC}$. About $170 \mathrm{MWt}$ of heat is transferred in the IHX and carried by the intermediate loop to the hydrogen process, which produces 0.64 million Nm3 (58 tonnes/day) hydrogen per day. The balance of the reactor thermal power is converted to electric power in the direct cycle gas turbine plant. About $12 \%$ of gross electricity generated is used in-house to supply the reactor plant and hydrogen plant uses.

Figure 2 shows the results of following electric demand increase, Ld, at $5 \%$ of base load per minute. Starting from the 

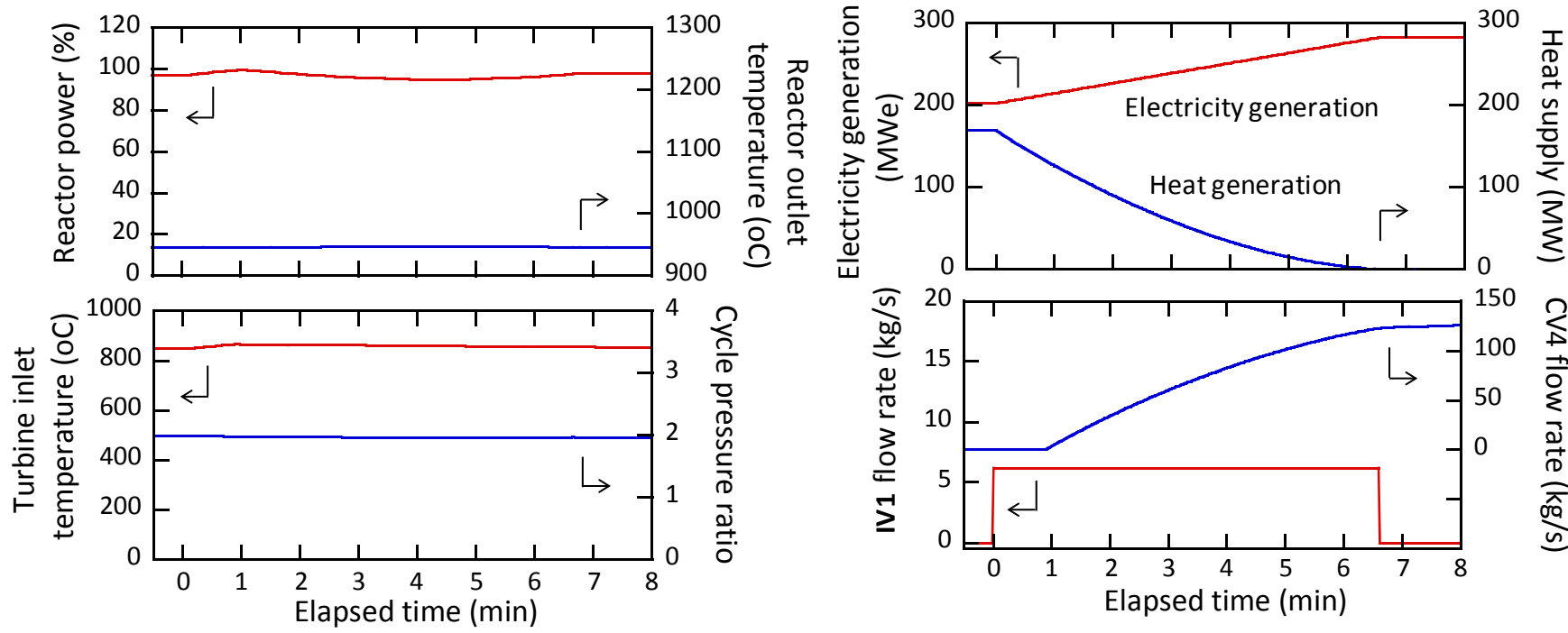

Figure 2: Simulation results of electric load following at 5\%/min.

base cogeneration parameters in Table 1, power generation is raised by opening inventory control valve IV1 to increase helium inventory in the primary circuit, which raises the turbine inlet pressure, $\mathrm{Pt}$, to 7 from $5 \mathrm{MPa}$. This is accompanied by reducing the hydrogen plant heat rate through reducing the intermediate loop flow circulation rate by the variable speed gas circulator. This causes the primary exit temperature of the IHX to increase. The load follow valve, CV4, is activated to maintain turbine inlet temperature constant by directing colder helium flow from the recuperator to mix with the hotter gas exiting the IHX so that the turbine inlet temperature is maintained closely to the rated $850 \mathrm{oC}$ as shown in Figure 2. The maximum power generated increases to 280 MWe, which is achieved in around 7 minutes. In the mean time, use of flow valve CV1 can effectively control the stability of turbine rotational speed with only minimum valve modulation. To return to the base cogeneration parameters, the above process is reversed by reducing helium inventory with IV2 in the primary coolant circuit and closing the load follow valve CV4 while increasing the hydrogen plant heat rate through the IHX. This has similarly been confirmed by simulation..

\section{CONCLUSION}

The results discussed in this paper lead to the conclusion of several salient features of the GTHTR300C. First, the reactor is operated near full power, as shown in Figure 2, during load follow such that the reactor control rod position is not changed. Second, the fuel temperature is not affected despite change in coolant pressure. This feature results from the core heat transfer that remains in a fully-developed turbulent flow regime in the load range of interest. Third, the reactor outlet coolant temperature, as well as reactor inlet coolant temperature (not shown in Figure 2), is kept constant, because rapid temperature transients are neither feasible, because of the large thermal inertia of the reactor core, nor desirable, because they cause thermal stress to the reactor equipment. The above three features show that any effect on reactor operation conditions is kept to minimum despite the considerable range of load following.
The last important feature is that the key gas turbine operating parameters including turbine inlet temperature (shown in Figure 2) and pressure ratio, which determine the operating point of the gas turbine, are unchanged such that the aerodynamic performance of both the turbine and compressor remains at their optimum design conditions. This means that the plant power generation efficiency remains constant. The GTHTR300C is thus shown to have the technical feasibility and economical advantage of performing flexible energy production including load following.

\section{REFERENCES}

1. Nickel, $H$. et al., Long time experience with the development of HTR fuel elements in Germany, Nucl. Eng. Des. 217, 141-151, 2002.

2. D. Greneche and W.J. Szymczakb, The AREVA HTR fuel cycle: An analysis of technical issues and potential industrial solutions, Nuclear Engineering and Design 236 (2006) 635-642.

3. Richards, Matt et al., VHTR Deep Burn Applications, 16th Pacific Basin Nuclear Conference (16PBNC), Aomori, Japan, Oct. 13-18, 2008, PaperID P16P1238

4. P.M. Williams, et al., MHTGR development in the United States, Progress in Nuclear Energy, vol. 28, No.3, pp.265-346, 1994.

5. A Technology Roadmap for Generation IV Nuclear Energy Systems, GIF-002-00, U.S. DOE Nuclear Energy Research Advisory Committee and the Generation IV (GIV) International Forum, December 2002.

6. GIF R\&D Outlook for Generation IV Nuclear Energy Systems, Gen-IV International Forum, 21 August 2009.

7. R. Jacques et al. Industrial Uses of Heat and Cogeneration - HTR Versus Conventional Processes, HTR-2010-003, Proc. Of HTR2010, Prague, Czech Republic, October 18-20, 2010.

8. M. G. McKellar et al., System Evaluation and Economic Analysis of a HTGR Powered High-Temperature Electrolysis Hydrogen Production Plant, HTR-2010-093, Proc. Of HTR2010, Prague, Czech Republic, October 18-20, 2010. 
9. J.R. Geschwindt et al., Performance and Optimization of an HTR Cogeneration System, HTR-2010-125, Proc. Of HTR2010, Prague, Czech Republic, October 18-20, 2010.

10. L. J. Lommers, AREVA HTR Concept for Near-Term Deployment, HTR-2010-132, Proc. Of HTR2010, Prague, Czech Republic, October 18-20, 2010.

11. Jean-Claude Gauthier et al., potential applications for nuclear energy besides electricity generation: a global perspective, Nuclear Engineering And Technology, Vol.39 No.1 February 2007

12. Long-term outlook of energy demand and supply in Japan - Estimation of energy demand and supply for "Nuclear Energy Vision 2100” of JAEA, JAEA-Research 2009-007, Japan Atomic Energy Agency, June 2009.

13. N. Sakaba et al., Examination on small-szed cogeneration HTGR for developing countries, JAEA-Research 2008-019, Japan Atomic Energy Agency, March 2008.

14. S. Saito, et al., Design of high temperature engineering test reactor (HTTR), JAERI 1332, Japan Atomic Energy Agency, September 1994.

15. K. Takamatsu et al., High Temperature Continuous Operation in the HTTR (HP-11) - Summary of the Test Results in the High Temperature Operation Mode, JAEA-Research 2010-038, Japan Atomic Energy Agency, November 2010.

16.X. Yan et al., GTHTR300 design and development, Nuclear Engineering and Design, 222(2-3), (2003) 247-262.

17. X. Yan et al., GTHTR300 design variants for production of electricity, hydrogen or both, Proc. 3rd of OECD/NEA Information Exchange Meeting on Nuclear Production of Hydrogen, Oarai, Japan (2005).

18. K. Kunitomi et al., JAEA's VHTR for hydrogen and electricity cogeneration: GTHTR300C, Nuclear Engineering and Technology, vol. 39, No. 1, pp.9-20 (2007).

19. K. Takamatsu et al., Development of Plant Dynamics Analytical Code Named Conan-GTHTR for the Gas Turbine High Temperature Gas-cooled Reactor, (I), Transactions of the Atomic Energy Society of Japan, 3(1), (2004) 76-87.

20. H. Sato, et al, Development of an evaluation method for the HTTR-IS nuclear hydrogen production system, Annals of Nuclear Energy, 36(7), (2009) 956-965.. 